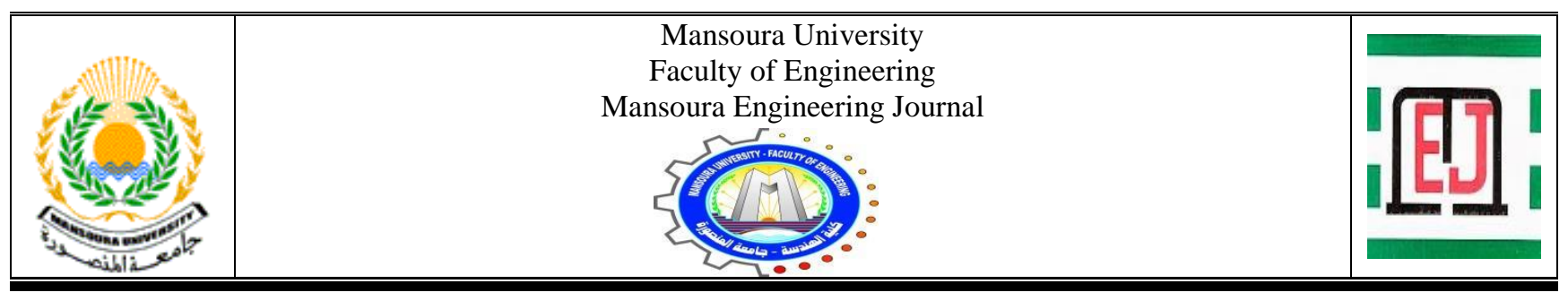

\title{
Challenges and opportunities of applying digital public participation tools in urban development projects in Egypt
}

\author{
Areej Kiwan*, Sherif Sheta and Mina Michel Samaan
}

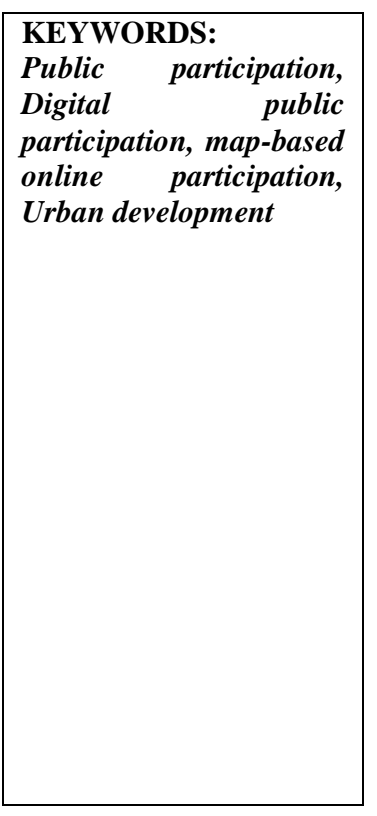

Abstract - Despite the rapid social and informal-urban growth which causes a lot of problems in urban and rural settlements in Egypt, the lack of both stakeholders' coordination and genuine public participation cause additional issues. Nowadays, many cities in Egypt, including the capital, suffer from the lack of real public participation in the decision-making of urban projects which results in conflicts among the government, the public and even experts opposing these decisions. All over the world, many participation models have been adopted in urban planning and development projects with different levels and forms of public participation. Where public participation is a requisite, not a choice, the debate is how to develop the participation models using the potentials of ICT's and smartphones to ensure inclusiveness in participation processes. At the Covid-19 pandemic, most of the activities have been shifted to online platforms. This shift has made an urgent demand for complete digital methods of public participation which -in addition- supports the Egyptian government vision for digitalizing services. In this regard, the research opens the door for applying digital public participation in urban development projects that reflects the public's needs and preferences, taking the advantages of the new technologies and considering the precautionary measures and social distancing in the age of covid-19. The paper explores the state-of-the-art of current online public engagement tools used in Egypt, the potentials and challenges of applying digital public participation and recommends guidelines for implementation based on successful case studies and what fits in the local context. 2021)

Received: (7 May, 2021) - Revised: (16 June, 2021) - Accepted: (30 June,

*Corresponding Author: Areej Kiwan, Teaching assistant \& MSC. student at the Architectural Engineering Dept. Faculty of Engineering, Mansoura University (e-mail: Areej.kiwan@mans.edu.eg)

Sherif Sheta, Vice Dean for Students and Educational Affairs at the Faculty of fine Arts, Associate Professor at the Architectural Engineering Dept. Faculty of Engineering, Mansoura University (e-mail: Sheriefsheta@mans.edu.eg)

Mina Michel Samaan, Lecturer at the Architectural Engineering Dept. Faculty of Engineering, Mansoura University (e-mail: samaan@mans.edu.eg).

\section{INTRODUCTION}

$\mathrm{R}$ ECENTLY, Egypt has witnessed repeated public disagreements regarding the urban development projects. The social media has appeared as a channel for declaring the public oppositions and demands regarding the implementation of these decisions on the ground such as the recent bridges projects in Cairo. This kind of public disagreement reflects the lack of public genuine participation and engagement in decision making. [1] [2] [3] Public participation concept aims at engaging the public in 123decision making mainly for keeping them at least informed, hear their voices, understanding their needs and 
manage any conflicts between stakeholders. [4] The public has real knowledge from experiencing their cities which should impact the decisions hand in hand with the specialists' experience. [5] A promising approach to facilitate public participation is the digital tools and online platforms. Information technology and digital tools have many potentials for bringing people together any time wherever they are. The pandemic proves that digital/online tools are needed, not choices to bring people together in the age of social distancing. Thus, alternative models of public participation needed to be reconsidered in urban development projects in Egypt, taking the advantages of the new technologies towards more wise collaborative decisions. For this purpose, the paper reviews the concept of public participation and how it has been shifted from the traditional methods to the digital ones. In addition, it reviews approaches of map-based engagement tools used in other cases. The paper is establishing a reference for applying digital participation tools through discussing the potentials and challenges of those tools and their applications and put recommendations for implementation in urban development projects.

\section{Public Participation In URban Planning}

"Public Participation can be any process that directly engages the public in decision-making and gives full consideration to public input in making that decision." -[6]

Public participation is not a new concept, it has been used in the traditional urban process and often appears twined with the shift from government to governance. Governance is defined as institutions holding authority where the public can express their opinions, interests, needs, manage their conflicts. The governance opens the door to new decision-making approaches that support multiple stakeholders' participation in decision making. [7] That has emphasized public participation importance as a key element of achieving urban governance and bearing potentials for more inclusive and sustainable decision-making processes. The interchangeability between the terms "Public participation" with "citizen participation" is no longer acceptable, "Public participation" is a more comprehensive term than "citizen participation" as it includes a wide range of beneficiaries even those who don't have the complete formal right of citizenship status and a wide range of public and civic participants. [8] Also, public engagement term is a broad one used for participation activities, while the term Public participation refers to a process along the lifespan of the project not just a single event for engaging the public and stakeholders and obtain their input to influence the decision making. [9] Public participation is always framed with issues of citizen empowerment, the right to the city and social justices. In the new urban agenda by Habitat III, A clear declaration was announced that the right of the city is a cross-cutting planning paradigm, where genuine participatory planning is one of the key tools towards wise urban development. It is considered a cornerstone of democracy and a part of citizens right to the city "The right of present and future inhabitants to occupy, use and produce just, inclusive and sustainable cities" with co-responsibility on both governments and people to demand their rights and promote them. [10]

\section{Advantages of PUblic Participation}

Public participation is a genuine tool for empowering people, hearing their voices and allowing them to shape their cities and lives [4], increasing the Sense of responsibility and ownership among people [11] building consensus and managing conflicts through dialogues between stakeholders and reaching understanding of the project and the other points of view [12] As citizen participation not only refers to citizen engagement but also experts, professionals in the fields of architecture, urban planning, engineering and other disciplines. This collaborative participation increases the city understanding and is widely reflected on setting more appropriate objectives [11], finding effective development scenarios, and shaping the city system and regulations. The process of the public engagement always include trainings and workshops for educating people about the projects and their objectives [12] and this helps in raising their awareness. Public participation helps in collecting public knowledge and learning from their experience. This public knowledge helps in understanding the context of the development projects from people who have really experienced it, this helps in widening the understanding of the planners and meeting the exact needs of the public. In addition, public participation offers great potential's for mobilizing actions and recruiting stakeholders. [5]

\section{LEVELS OF PUBLIC PARTICIPATION}

The Public participation follows many levels of public engagement according to the level of empowering people in making decisions. One of the most cited references for citizen participation is the "Ladder of participation" by Arnstein within the civil movements in the US in 1969. She outlined the ladder of citizen participation in eight stages (rungs). These levels were later categorized into four levels according to the level of public impact in decisions as shown in fig (1) [13]

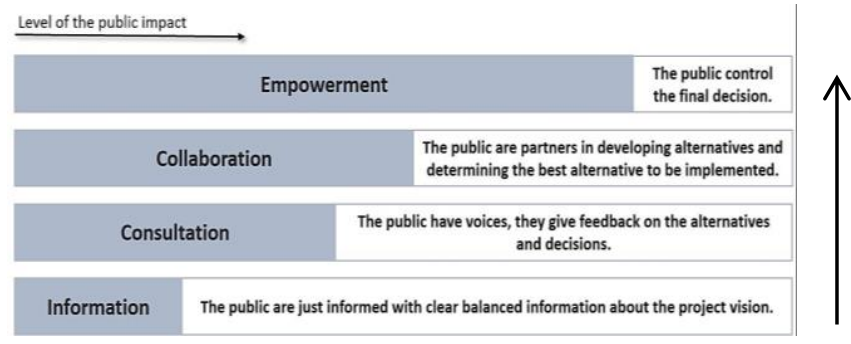

Fig. 1. Levels of public participation (the Author) 
Many countries working seriously in implementing citizen participation frameworks for urban decision making following new tools and techniques for improving the public engagement process. There are some obstacles and limitations in traditional public participation frameworks that face the public, governments and planners such as: time and effort spent in the participation processes, fixed time and location, the level of trust, financial resources and management of conflicts between different perspectives and interests. Fixed time and location may not be suitable for all which affect inclusiveness of participation, also, the public interest and trust in the whole participation process play a great role participation rates. [5]

\section{THE SHIFT FROM TRADITIONAL TO DIGITAL PARTICIPATION METHODS}

Traditional public participation refers to the common forms of participation such as face-to-face meetings, paper questionnaires, and discussions among stakeholders and selected groups representing the community in participation workshops. Since traditional participation methods have been criticized due to their aforementioned limitations [5], new types of participation systems are always updated with the Information \& communication technologies developments and expansion of internet and social media. In mid of 1990s, examples of participation methods were developed using GIS technologies. As an example of early interventions, Shiffer provided the public an access to a digital collaborative planning system through multi-media planning tools. [14] And concluded that the increase in the public access to the shared information led to more communication among the participants and affected the decisions. Shiffer's system led to the development of more web-based participatory mapping tools [15] Information \& communication technologies (ICTs) developments in Geographic Information Systems, digital geographic data, GPS and mobile data platforms have raised the interest in new methods of digital public participation in urban planning developing. [16]

\section{Digital Public Participation}

Digital participation forms facilitate many issues in comparison to traditional ones. Digital and online platforms help planners in collecting data, information, needs, opinions, analyzing data and visualizing the public inputs for planning and policy making. Collected data can support other tools for modeling, visualizing and predicting the future of the projects and planning decisions in the future from different perspectives. In addition, they give a real power for mobilizing discussions through the community, gaining citizens' support.

\section{AdVantages of digital PUblic Participation}

Many forms of digital participation have been developed and used for engaging the public for achieving digital participation advantages:

A. Facilitating inclusive planning process: by engaging diverse and wide range of participants, and support communication among them. [17]

B. Crowdsourcing \& Gathering local knowledge: crowdsourcing is a way of collecting local knowledge from a wide scale of the public and use this community intelligences for reaching proper solutions and visions. [18] Online participation tools facilitate gathering local knowledge from the public through online platforms by asking questions, doing surveys or opening interactive discussions.

C. Building consensus: Some researchers argue that online participation tools allow people to participate with a proper interval of time to think, respond and resolve their misunderstanding. In addition, online open discussions offer a chance for people to keep them updated and to share their thoughts and ideas in a comfortable environment.[5]

D. Mobilizing actions: Online platforms help in gathering or sharing ideas among a wide range of public, building trust, help communities in self-organizing and networking among local community channels. Planners can benefit from mobilization tools for different purposes such as promoting new urban trends that requires people interest and participation such as cycling, greening, etc. In addition, these tools help in recruiting more active stakeholders. [5] One of the evidence of the power of online tools in mobilizing actions is the so-called Arab spring, where social media play the main role in gathering the opposition groups. [19]

E. Informing and communication with/among the Public [21]: the capability of online tools in informing the public about the urban planning projects is one of the largest potentials of online participation. Online platforms and social media offer flexibility in spreading and engaging more people with fewer limitations of time and space compared with traditional forms. [20] In addition to Access to online interactive planning documents by offering tools for the public to check new policies on maps, where each policy is attached to the places in the city affected by it, rather than reading long documents to find certain policies. [21] This helps in keeping people updated, aware and attached to the urban issues and increases their sense of responsibility and ownership. 
TABLE 1.

RESPONSE OF ONLINE PARTICIPATION TOOLS TO THE PUBLIC PARTICIPATION GOALS (THE AUTHORS)

\begin{tabular}{|c|c|c|}
\hline $\begin{array}{c}\text { Targeted } \\
\text { participation } \\
\text { goals }\end{array}$ & Opportunities & Limitation \\
\hline $\begin{array}{l}\text { Inclusive } \\
\text { planning }\end{array}$ & $\begin{array}{l}\text { - Diversity of participants } \\
\text { - Support discussions and } \\
\text { communication among } \\
\text { the stakeholders }\end{array}$ & $\begin{array}{l}\text { - The privacy of the } \\
\text { participants' data. } \\
\text { - Technology illiteracy } \\
\text { - Digital divide }\end{array}$ \\
\hline $\begin{array}{l}\text { Informing \& } \\
\text { Communicati } \\
\text { on with } \\
\text { public }\end{array}$ & \begin{tabular}{|l} 
- Online tools help \\
increasing the reach to \\
wide range of the \\
community through \\
social media, etc. \\
- Educating people \& \\
raising awareness.
\end{tabular} & \begin{tabular}{|lr} 
- Using the online \\
platform for \\
promoting successful \\
projects instead of \\
focusing \\
participation \\
processes.
\end{tabular} \\
\hline $\begin{array}{l}\text { Building } \\
\text { consensus }\end{array}$ & \begin{tabular}{|l} 
- \\
- Bunaging conflicts \\
understanding of the \\
project
\end{tabular} & $\begin{array}{l}\text { - Creating conflicts in } \\
\text { discussions }\end{array}$ \\
\hline $\begin{array}{l}\text { Learning } \\
\text { from the } \\
\text { public }\end{array}$ & 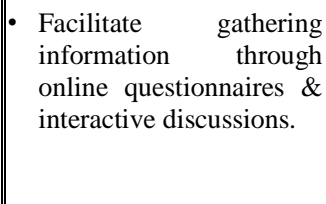 & \begin{tabular}{||l} 
- Technology illiteracy \\
\& digital divide \\
- Difficulties \\
collecting in \\
analyzing data and \\
ensuring its accuracy.
\end{tabular} \\
\hline $\begin{array}{l}\text { Mobilizing } \\
\text { actions }\end{array}$ & $\begin{array}{l}\text { - gathering or sharing } \\
\text { ideas among wide groups } \\
\text { of people } \\
\text { building trust, help } \\
\text { communities in self- } \\
\text { organizing } \\
\text { Networking among local } \\
\text { community channels. }\end{array}$ & $\begin{array}{l}\text { Misusing \& misleading } \\
\text { of the community. }\end{array}$ \\
\hline
\end{tabular}

\section{FORMS \& LEVELS OF DIGITAL PUBLIC PARTICIPATION}

There are many approaches of digital/online participation implemented around the world. These approaches are determined according to the type of the project, level and purposes of participation process. In addition to technical features, the implementation process and the way of managing the process. Mainly digital public participation in urban planning are based on Geographical information systems (GIS). However, Geographical information system used for public participation is named PPGIS, which offers the chance for exploring the available spatial information, collecting data and interacting through the planning process.

Forms of digital public participation -as aforementioned in the main concept of public participation- differ according to many issues including levels of digital participation which consequently figure the forms and the needed tools.

1. Informative level: providing access to relevant data and information for informative participation where the public have the right to know such as e-newsletters, websites and e-mails. Some cities provide fully functional GIS, where citizens can get access to a variety of data and information of a certain site but without interaction, such as information about developing projects, locations and addresses. (One-way channels)

2. Online discussions: A higher level of digital participation includes two way communication between decision makers and the public. This level includes informing the public and asking them for their feedbacks and suggestions. There are many methods for this approach such as social media channels (Facebook, twitter and linked-in, etc.), virtual meetings and blogs with shared visions and plans drafts.

3. Map-based discussions \& surveys: these forms offer communication on the basis of an online map, where the public can suggest and leave feedbacks on certain locations on the map. (This forms are discussed further in the paper)

4. Involvement in decision making: As the highest level of participation, the public contribute in the decisions through voting on decisions or development scenarios through voting for yes or no, or vote for the best scenarios to be implemented. [20] [21] [22]

\section{MAP-BASED ONLINE PUBLIC PARTICIPATION}

In this paper, the focus is on the map-based online public participation methods such as geo-mapping, geoquestionnaires and geo-discussions. These tools are used for mapping the public needs, preferences and demands on online interactive maps instead of face-to-face or physical meetings and workshops as two-way communication channels. They are chosen in particular according to their potentials of simplicity and familiarity to the public and suitable for introducing digital public participation in the community.

\section{A. Categories of online public participation platforms:}

According to [5], Online public participation platforms can be classified into two main categories based on who manages the participation as:

\section{1) The Participant-led:}

These platforms are managed by the public and used for various purposes. Planners use these platforms for engaging citizens in the planning process and discussing new ideas online without gathering in a meeting room. These platforms can be Facebook groups or community forums used by citizens or specific neighborhood residence for communicating. www.Nextdoor.com is an example of these platforms in the US.

\section{2) Planner-led:}

They are applications and websites developed for public participation purposes. These platforms are led and managed by planning organizations such as planning departments, research labs and private planning firms. They are used for informing the public, gathering their needs and opinions, and attracting their attention to planning issues. They may allow anonymous engagement or control it by asking the participants 
about basic data (e.g. age, zip code, gender ...). Also, these platforms can provide data about projects or neighborhoods based on crowd-sourcing or official data sources, some provide a way for interaction and discussions about certain issues, and other technologies allow discussing ideas through open-ended questions. Citizen lab (www.citizenlab.co/), Mind Mixer (www.mindmixer.com), and changify (www.changify.org) are examples of these platforms.

The main difference between the two plateforms is who manages the platform. As discussed before, Participant-led platfroms is managed by the community, and planners are invited to join and the opposite with the Planner-led platforms. Participant-led platfroms are strong tools for mobilizing communities for supporting and implementing planning projects compared with Planner-led platfroms. Participant-led platfroms can help more in building consensus than Plannerled platfroms can do. Also, Additional Face-to-face meetings can enhance building consensus if they are possible. Plannerled platfroms can build a strong and well-organized information gathering process which can be used as data for future planning decisions.

\section{B. Forms of map-based online public participation}

\section{1) Public Geo-mapping:}

This kind of Geo-maps depends on crowed-sourcing; the data added by the public in the maps may be related to the current state of their cities, needs, problems or even mapping of important events within the city. FixMyStreet platform is an example of websites which enable people to report street problems in their city then these reports are sent to the authorities for fixing. [23] Another mapping tools for understanding the public experience in a space and crowdsourcing is emotional map. Emotional map is defined "as understood in the field of participatory planning, is a method that allows citizens and municipalities to initiate a map-based dialogue concerning". An online Emotional mapping was held in Prague in 2016 to improve safety in the district with online tools. The current and future state of public space, drawing upon their experiences of that place." The municipality decided to organize a largescale safety mapping for the schools pupils in the district. Before mapping, students were asked to fill their basic information such as school, gender, grade and the way they filled in the map (alone or at school or with parents), these data were used for analyzing their replies. The online map was created with five spatial questions for examining safety around the schools by students, fig (2):

- This is my path to school (line)

- I am afraid of cars here (point + comment)

- It is uncomfortable here (point + comment)

- I like it here (point + comment)

- I spend my free time here (point + comment) [24]

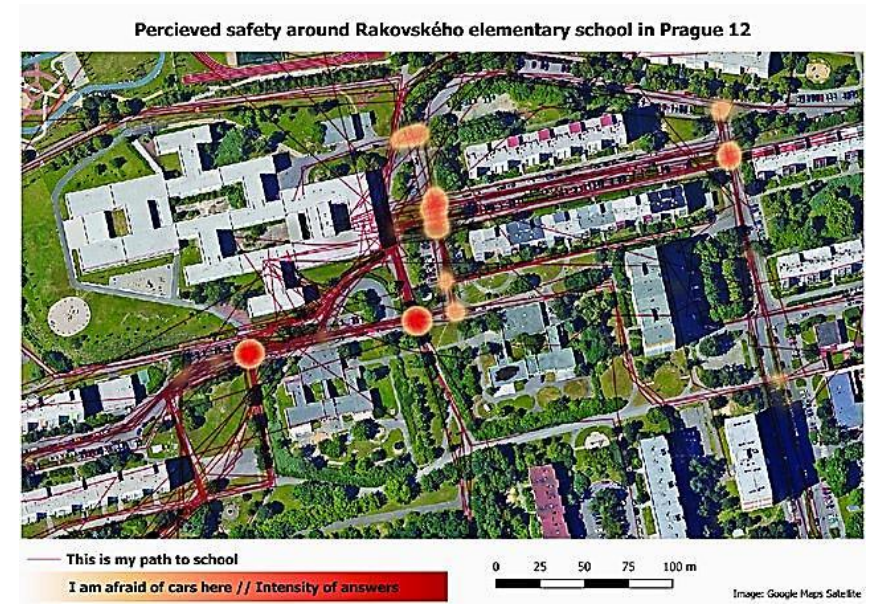

Figure 2. Safety map [24]

\section{2) Geo-questionnaires:}

The concept of Geo-questionnaire tool is based on combining the standard questionnaire with a map, for the purpose of gathering data about the public interests and preferences within a certain city space. The Geo-questionnaire tool provides the participants with point, line and polygon sketching tools for answering the questionnaire questions on an interactive map, which offers simple navigation tools such as zoom in, zoom out, and pan functions, as well as selection of base map layers. This geo-questionnaire in itself should be simple and user-friendly and can be available in the form of mobile applications. The collected information and replies on questionnaires are stored in database for further analyses. Geoquestionnaires help in participating for different purposes such as creating maps of local need, understanding the mobility behaviors, rehabilitation conceptions, etc.

\section{Example:}

One of the examples is preparing local needs map for the city center of Poznań City in Poland in 2016, fig (3). The aim of the geo-questionnaire was made to specify the needs and expectations of inhabitants of the region in various fields such as development of public spaces, safety, and infrastructure development. The questionnaire was addressed to all inhabitants of Poznań city, with results of 709 applications $(0.58 \%)$ from 122.5 thousand inhabitants of the city center living on 1,680 ha. The results are also used for the implementation of Poznań City Center Renewal and Development project (2014-2030). The qeo-questionnaire includes: (a) personal data, (b) sites visited in Poznań city center (c) mobility (d) evaluation of dwelling conditions, (e) evaluation of the space quality, (f) evaluation of the geoquestionnaire. The project uses multi tools for participants recruitment, the results showed the percentage of effectiveness of each according to the participants replies: Social media (58.7\%) Internet information portals $(9.7 \%)$ City Hall website (4.2\%). [16] [25] 


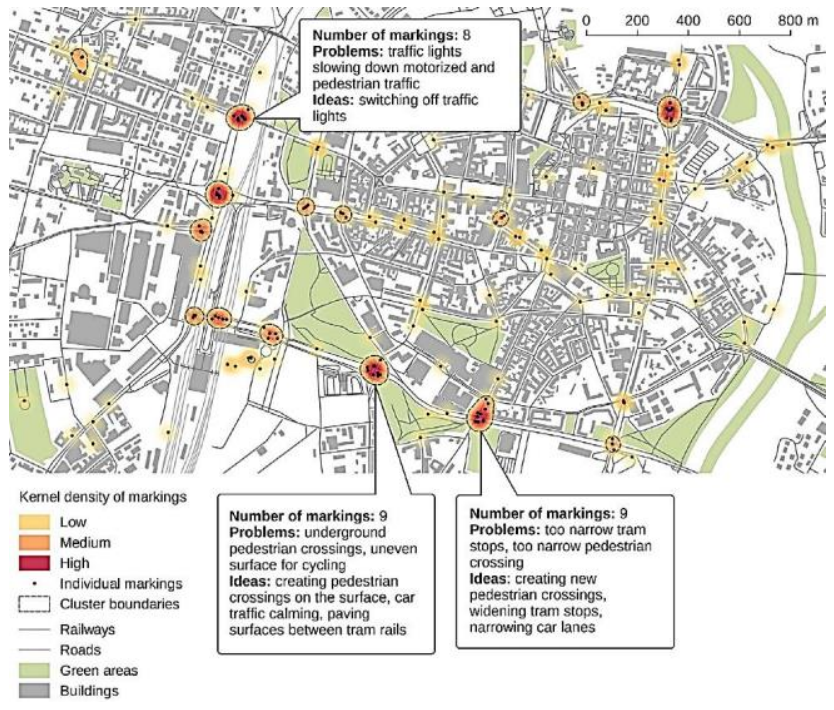

Figure 3. Local needs map, The markings represent places evaluated negatively in respect to mobility in downhall Poznan. [26]

\section{3) Geo-discussions:}

For the Geo-discussions, Argumentation maps offer an interactive interface including both maps and discussions. [5], participants are allowed to select map objects, sketch objects (point, line and polygon) on a map in response to discussion posts. Also, they can select a site and attach opinions in text/sketch form, which can be reviewed by everyone on the platform. Geo-discussions enable participants to communicate instead of the one way communication in the geoquestionnaires.

\section{Example:}

A Geo-discussion was carried out in Łód'z in Poland, aimed at collecting feedback on the performance of public transportation system, it was held after the implementation of development plan for asking people about their feedbacks, fig(4). The discussion has lasted for 12 days. The participants were provided with a map of the area and asked to pin their opinions by sketching (a point, a line or a polygon) with openended questions to describe the sketches. The project used multiple Methods of recruitment: 1 . social media 2. Websites 3. Local media and got 1390 responds ( $0.2 \%$ of inhabitants) [16]

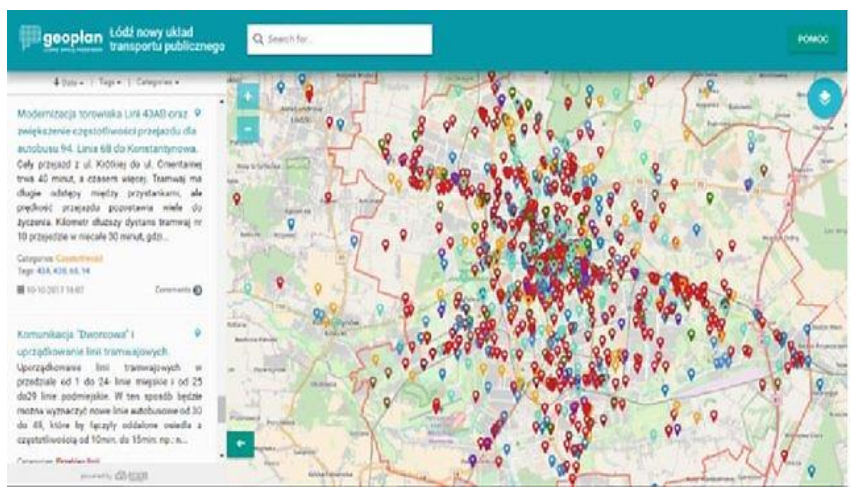

Figure 4. the application used in the Łód'z public transportation case [16]
TABLE 2 .

COMPARISON BETWEEN GEO-QUESTIONNAIRE AND GEO-DISCUSSIONS (THE AUTHORS)

\begin{tabular}{|c|c|c|}
\hline $\begin{array}{l}\text { Point of } \\
\text { comparison }\end{array}$ & Geo-questionnaire & Geo-discussions \\
\hline Form & $\begin{array}{l}\text { Web-based questionnaire } \\
\text { with a sketchable map }\end{array}$ & $\begin{array}{l}\text { Discussions forums on } \\
\text { an interactive map }\end{array}$ \\
\hline Method & $\begin{array}{l}\text { Through text questions on } \\
\text { the map, the public } \\
\text { answers by text and } \\
\text { sketching points, lines or } \\
\text { polygons on certain } \\
\text { locations on the map }\end{array}$ & $\begin{array}{l}\text { Open discussions on } \\
\text { different issues, the } \\
\text { public communicate } \\
\text { through comments, } \\
\text { uploading attachments } \\
\text { or leaving comments on } \\
\text { certain locations on the } \\
\text { map. }\end{array}$ \\
\hline Interaction & $\begin{array}{l}\text { One way communication } \\
\text { with no interaction } \\
\text { between the public }\end{array}$ & $\begin{array}{l}\text { Enable communication } \\
\text { between the public }\end{array}$ \\
\hline $\begin{array}{l}\text { Managing } \\
\text { data }\end{array}$ & $\begin{array}{l}\text { Categorized data - Easy } \\
\text { to analyze }\end{array}$ & $\begin{array}{l}\text { Uncategorized data } \\
\text { Hard to analyze }\end{array}$ \\
\hline Purpose & $\begin{array}{l}\text { - Exploring the public } \\
\text { needs \& preferences } \\
\text { - Understanding the } \\
\text { urban context through the } \\
\text { public experience } \\
\text { - Public voting, etc. }\end{array}$ & $\begin{array}{l}\text { Collecting feedbacks, } \\
\text { suggestions } \\
\text { recommendations from } \\
\text { the public }\end{array}$ \\
\hline
\end{tabular}

No training is needed for public - Users only need to be familiar with map reading and applications browsing.

\section{Public Participation in Egypt (A State OF art)}

Before 1990s, most governments in developing countries depended mainly on top-down strategies in decision0making. Participation was brought to Egypt in 1994, when the Egyptian government started a bottom-up program with Germany, Focusing on community participation as a main issue for upgrading urban poor areas. In 1996, Participation was brought again by the United Nations in Al-Darb AlAhmar project, and in 1998, Egypt signed an agreement with the Federal Republic of German (Participatory Development Program (PDP)) till now. The PDP was implemented by the GIZ in cooperation with the Ministry of Housing, Utilities, and Urban Communities, it is one of the first and main participatory planning initiatives in Egypt providing both technical and financial support, In addition, The Egyptian government agrees on the World Bank model for participation in development for empowering people with the collaboration of the government, the civil society and the private sectors. Along with the trend of decentralization and participatory approaches in decision-making, the general organization for physical planning GOPP initiated the strategic plans for the Egyptian cities and villages following the standard of public participation in co-operation with the United Nations program for the urban settlements in Egypt (UN-Habitat) and the institute of housing research. [26] [27] [28] 


\section{EXAMPLES OF DigITAL/ONLINE PARTICIPATION IN EGYPT}

Recently in Egypt, there is a package of digitalizing initiatives for the government's services represented in new mobile applications available for the public. Besides, a number of online platforms and mobile applications have succeeded and spread among people, some of them offered by the government, start-ups and companies for different purposes such as collecting needs, reporting accidents and promoting services. These attempts are good potentials for introducing genuine digital participation tools for the public and overcoming the poor levels of public participation in urban development projects.

\section{A. Fe khedmetak - IDSC Egypt:}

One of the worthwhile examples of online citizengovernment platforms is the Stevie Awards winner: "Fe Khedmetak- mobile application, initiated directly by the Egyptian Prime Ministry as a communicating channel with citizen, fig (5). This service is introduced to the public in form of website and mobile application. The application -as well as the website- is used for tracking the citizens' complaints and needs, by introducing a fill form for each complaint. The form ask for basic information of the citizen (Name, national no., date of birth, etc.) then the reported problems details with their written locations. After that, the application direct the report to the responsible organization to deal with. Also, it offers an opportunity for enquiries and the government announcements. [29]

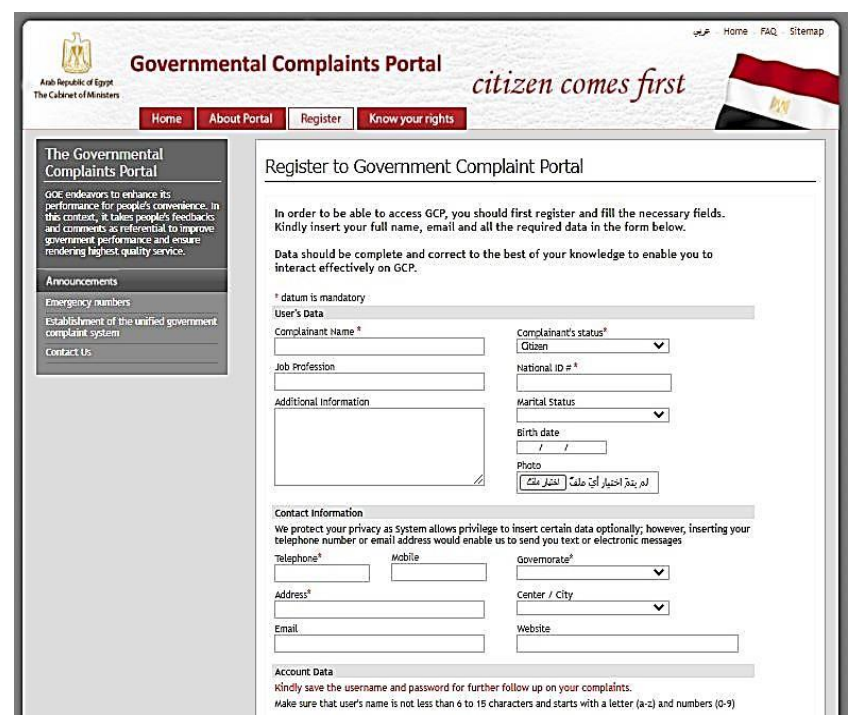

Figure 5. T The citizens' complaint application at www.shakwa.eg [29]

\section{B. Street Guards website:}

Street guards is a Crowd Sourcing tool that aims at collecting crowdsourced data that can be used to encourage governorates to take actions for improving streets and cities' livability fig (6). The public can map the location of different accidents such as infrastructure issues, threatening and cars accidents. The website interface is an interactive map that shows the public reports on different locations. The users can zoom in at the site of the accidents and pin the location of his issue, then the website asks the reporter some questions about: the Date, type of accident with fixed three options of reports (Crash/Near Miss - Threatening Incident - Infrastructure Issue), type of the place of the accident (Road Sidewalk-BusBike lane-or other), The contact of the reporter, A text box to type more about what happened and to add photos or videos of the accident or the issue. All the reports are shown on the map and available for all to check without any details of the issues reporters [30]

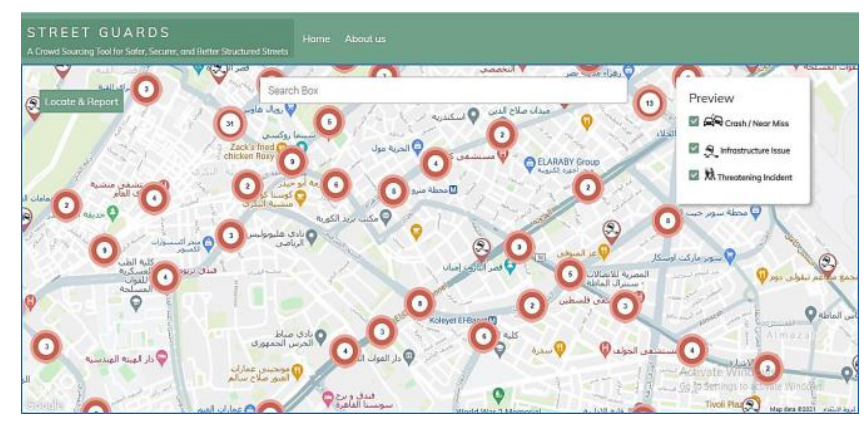

Figure 6. Street Guards interface Street [30]

\section{DAWAR application:}

DAWAR is an application developed by Environ-Adapt Company in partnership with GIZ and the ministry of Environment for the purpose of waste collection and street cleaning. The application depends on crowdsourcing where the public can report the place of waste accumulation in their district by capturing a photo of the area and adding the location by GIS, then the report is sent to the responsible company in this district to collect the waste, then attach a picture of the cleaned site back on the application for the users to review. Beside waste collecting services, the application offers updates about workshops related to the field of waste management, marketing for Eco products and a timeline fed with news in the related fields. [31]

\section{WHAT HINDERS PUBLIC PARTICIPATION IN EGYPT?}

In Egypt, Public participation is almost informative at the national level where the real lack of participation is most obvious at the local level. In many urban development cases, participation is used for getting fund and support of the international organizations that require participation in their funded projects, and for gaining the public support for politicians. one later Evidence of the aforementioned, the Strategic Master Plans implemented by the General Organization of Physical Planning (GOPP), where the planning process was developed with a participatory model through media campaigns, telephone voting and public discussions. Though, the process was almost centralized with no space for real local dialogue. [28] Number of factors 
mainly affects the participation and can explain the poor public participation in Egypt:

1-Legislations: The new building law no.119 (suspended till the preparation of new version) refers to public participation and involvement of local stakeholders in strategic planning. The law is not extensively declaring the importance of public participation. Administrative systems such as local government units (LGUs) suffer from many issues hindering participation, mainly the lack of qualified stuff that is able to manage and implement participation processes. Hence, a serious attempt for developing laws and practices is needed towards enabling sufficient participation and decentralization of decision making.

2-The public interest: one of the main reasons for the lack of public participation is the centralization of decision-making and the lack of trust between people and the government. If the public do not witness real public empowerment models for sufficient time, the public willingness to participate and their sense of responsibility are affected. The rates of voters in the Egyptian People's Assembly in 2015 as an example were only $28.27 \%$ [32], which reflects the low interest of the public in participating.

3-Economic factors: It is proved based on many participation practices that the economic conditions of the public affect the rate of participation. Population living below national poverty line equals $32.5 \%$ with $41.4 \%$ employment to population ratio according to HDR 2020. [33]

4-Social factors: Level of education is a key issue in participation as illiterate people are unable to participate in complex participation process. Literacy rate in adult (\% ages 15 and older) is $71.2 \%$ in Egypt in 2020. [33] In addition, a great effort is needed for educating the public about the importance of participation process, how to participate and how far their voices will impact the decisions. Also another important issue to take in consideration regarding to the online participation is the digital literacy. In Egypt, $46.9 \%$ of the population have access to the internet with 95.3 per 100 people use mobile phones, which is a promising ratio. [33] [26]

\section{CONClusion:}

Although the Digital public participation tools have proved their efficiency in many public participation processes in many countries, the research on these digital participation technologies is still maturing. New tools and methods of implementations follow the development of technology tools. Introducing digital tools for public participation in Egypt has many potentials for fulfilling the public participation's main goals sufficiently.

It ensures the inclusiveness of the public participation processes by reaching a wide variable range of participants and bring all stakeholders together regardless of where and when. Besides, Digital public participation has appeared as an urgent need because of the precautionary measures and social distancing. There are also issues to take into consideration regarding the use of digital tools such as technology literacy, the digital divide and the privacy of public data. However, these issues should be treated as challenges, not limitations, to ensure the efficiency of the participation process. Planners and decision-makers should adopt these tools to the community, as they should frame the public participation process and its tools. The legislation, economic and social aspects like the rates of technology literacy, public interest and trust all are factors to deal with wisely in framing the public participation process. It is also important to start with the most familiar tools and methods to the public. In addition, it is important to shed the light on public participation in urban development, not only by mentioning it in the laws and legislation but also to be declared clearly and activated in practice. In this regard, the paper draws attention to this in the newly developed building law in Egypt. The research opens the door for applying digital tools in urban development projects and encourages further applied research in urban development projects for examining its efficiency for developing and adopting successful frameworks.

\section{RECOMMENDATIONS:}

Based on the conclusion and the previous case studies, the research recommends the following steps for implementing digital public participation in the urban development projects in Egypt:

- Ensure that the process, methods and tools of digital public participation fit the local context based on real understanding of the challenges and problem scenarios.

- Defining the objectives and the purpose of the participation process is essential for deciding the most proper steps of implementation with the consultancy of the other stakeholders before finalizing the process framework.

- Defining the process objectives that support stakeholders' determination, and when and how to involve them through the urban planning process.

- In short-term projects, there may not be a need for a management board; however, some arrangements for the process are essential such as team structuring, stakeholders mapping with whom will do what? In addition, operational, general rules and general policies help the process be self-monitored.

- In the participation process, the importance of leadership is directly proportional to the level of participation. Some projects with an early level of participation don't require leadership and can be managed by the planners.

- Identifying \& Understanding the target groups 'social, demographic, digital literacy, level of trust, age, background, etc., is critical in determining the public participation methods and tools.

- Promoting the process and building trust on it among the community is a vital issue to ensure the effectiveness of the participation process, such as informing the public about the purpose of the 
participation, level of engagement and how their voices will influence decisions.

- It is fine to start with using simple proper cost process (using social media as an example is with less/no cost), taking the chance to educate the public about the process and new tools for them.

- It is important to set guidelines and agendas regarding to the process: a) coordinating the use of digital collected data with the available data at the local organizations such as the local authorities, GOPP, research organization, etc. b) Guidelines and strategies for integrating online participation tools with the planning process, and c) Guidelines for educating the participants about the process and how to protect their identity and privacy.

- A key challenge of public participation in Egypt is to ensure highly inclusive and diverse engagement specially the marginalized groups. It is axiomatic that more diverse create more conflicts, thus declaring roles and agendas for conflict management is needed.

- Choosing proper technologies and platforms with wider outreach is important to ensure a wide range of people are informed. Merging offline/online participation can be in some cases needed to avoid digital divide gab, besides offering educational materials for the public to stand up to digital illiteracy.

- Finally, assisting the whole process is important for developing better scenarios for the participation process in all its stages, and creating well customized roadmaps and guidelines for future processes in both research and practices.

\section{Authors ConTribution}

Areej Kiwan,

1-Conception and design of the work

2-Data collection and tools

3-Data analysis and interpretation

4-Methodology

5-Drafting the article

6-Final approval of the version to be published

Sherif Sheta and Mina Michel Samaan,

1- Conception of the work

2- Methodology

3- Supervision

4- Critical revision of the article.

\section{REFERENCES}

[1] A. Radwan and A. Saber, "Assessment of the Urban and Environmental Impact of the Traffic Axes Development Project of Heliopolis," Bulletin of the Faculty of Engineering Mansoura University, vol. 45, pp. 42-57, Nov. 2020, doi: 10.21608/bfemu.2020.122375.

[2] "BBC," Apr. 2021. https://www.bbc.com/arabic/trending-53492009 (accessed Apr. 10, 2021).
[3] "Elhora," Apr. 2021. https://www.alhurra.com/egypt/ (accessed Apr. 10, 2021).

[4] E. van Beckhoven, B. van Boxmeer, and H. Szemzö, "Local Participation in Large Housing Estates: A Comparison of the Netherlands, Spain and Hungary," in Mass Housing in Europe: Multiple Faces of Development, Change and Response, R. Rowlands, S. Musterd, and R. van Kempen, Eds. London: Palgrave Macmillan UK, 2009, pp. 213-234. doi: $10.1057 / 97802302747239$.

[5] N. Afzalan and B. Muller, "Online Participatory Technologies: Opportunities and Challenges for Enriching Participatory Planning," Journal of the American Planning Association, vol. 84, pp. 162-177, Apr. 2018, doi: 10.1080/01944363.2018.1434010.

[6] O. US EPA, "Public Participation Guide: Online Self-Study Modules," US EPA, Jan. 02, 2018. https://www.epa.gov/internationalcooperation/public-participation-guide-online-self-study-modules (accessed Mar. 09, 2021).

[7] J. Kibuuka et al., Urban Decision-making and Expert Integration. 2015.

[8] K. Quick and J. Bryson, "Theories of public participation in governance," 2016, p. Chapter 12.

[9] S. Pinpoint, "Community Engagement, Public Participation, Civic Engagement - Let's define these terms," Social Pinpoint - A Place to Engage Your Community, Sep. 08, 2017. http://www.socialpinpoint.com/blog/community-engagement-publicparticipation-civic-engagement-lets-define-these-terms/ (accessed Mar. 09, 2021).

[10] on H. and S. U. D. UN Conference, "Habitat III Policy Papers: Policy Paper 1 The Right to the City and Cities for All," in United Nations Conference on Housing and Sustainable Urban Development, United Nations, 2017, p. 92. [Online]. Available: http://www.habitat3.org/

[11] G. Farouk Hassan, A. Hefnawi, and M. Refaie, "Efficiency of participation in planning," World Pumps, vol. 50, pp. 203-212, Jun. 2011, doi: 10.1016/j.aej.2011.03.004

[12] R. Irvin and J. Stansbury, "Citizen Participation in Decision Making: Is It Worth the Effort?," Public Administration Review, vol. 64, pp. 55-65, Feb. 2004, doi: 10.1111/j.1540-6210.2004.00346.x.

[13] B. Stelzle and J. Noennig, "A Database for Participation Methods in Urban Development," Procedia Computer Science, vol. 112, pp. 24162425, Dec. 2017, doi: 10.1016/j.procs.2017.08.173.

[14] M. Shiffer, "Interactive multimedia planning support: moving from standalone systems to the World Wide Web," Environment and Planning B: Planning and Design, vol. 22, pp. 649-664, Jan. 1995, doi: 10.1068/b220649.

[15] R. Kingston, "Web-based PPGIS in the United Kingdom," 2002. doi: 10.1201/9780203469484.ch8.

[16] P. Jankowski et al., "Geoweb Methods for Public Participation in Urban Planning: Selected Cases from Poland: Volume Eight," 2019, pp. 249269. doi: 10.1007/978-3-030-04750-4_13.

[17] N. Afzalan and J. Evans-Cowley, "Planning and Social Media: Facebook for Planning at the Neighbourhood Scale," Planning Practice and Research, vol. 30, May 2015, doi: 10.1080/02697459.2015.1052943.

[18] D. Brabham, "Crowdsourcing the Public Participation Process for Planning Projects," Planning Theory, vol. 8, pp. 242-262, Jul. 2009, doi: 10.1177/1473095209104824.

[19] M. Lim, "Clicks, Cabs, and Coffee Houses: Social Media and Oppositional Movements in Egypt, 2004-2011," Journal of Communication, vol. 62, Apr. 2012, doi: 10.1111/j.14602466.2012.01628.x.

[20] L. Mandarano and M. Meenar, "e-Participation: Comparing Trends in Practice and the Classroom," Planning Practice and Research, vol. 30, Mar. 2015, doi: 10.1080/02697459.2015.1017933.

[21] R. Kingston, "Public Participation in Local Policy Decision-Making: The Role of Web-Based Mapping," Cartographic Journal - CARTOGR J, vol. 44, May 2007, doi: 10.1179/000870407X213459.

[22] R. Steinmann, A. Krek, and T. Blaschke, "Can Online Map-Based Applications Improve Citizen Participation?," in E-Government: Towards Electronic Democracy, Berlin, Heidelberg, 2005, pp. 25-35.

[23] "FixMyStreet." https://www.fixmystreet.com/ (accessed Jun. 12, 2021).

[24] J. Panek, "Emotional Maps: Participatory Crowdsourcing of Citizens 'PerceptionsCitizens'Perceptions of Their Urban Environment," Cartographic Perspectives, vol. 90, May 2018, doi: 10.14714/CP90.1419.

[25] E. Bąkowska-Waldmann et al., "Geo-questionnaire in urban planning preliminary results of the experimental application in Poland," Rozwój Regionalny i Polityka Regionalna, vol. 35, pp. 37-54, Jun. 2017.

[26] M. Czepkiewicz, P. Jankowski, and Z. Zwolinski, "Geo-Questionnaire: A Spatially Explicit Method for Eliciting Public Preferences, Behavioural 
Patterns, and Local Knowledge - An Overview," Quaestiones Geographicae, vol. 37, pp. 177-190, Sep. 2018, doi: 10.2478/quageo2018-0033.

[27] H. Mahmoud and A. Arima, "The Public Participation Policy as a New Approach to Solve the Urban problems in Egypt: A Case Study on Asyut city," Journal of Habitat Engineering (JHE), vol. 2, pp. 75-86, Sep. 2010.

[28] D. Shehayeb and K. Abdelhalim, "Issues of Participation in Egypt," Journal of Architectural and Planning Research, vol. 29, pp. 45-64, Mar. 2012.

[29] A. Menshawy, A. Salman, and O. Eid, "ASSESSMENT OF PARTICIPATORY URBAN DEVELOPMENT APPROACHES IN EGYPT "TOWARDS MORE JUST CITIES,", Journal of Al-Azhar University Engineering Sector, vol. 14, pp. 1089-1107, Jul. 2019, doi: 10.21608/auej.2019.43424

خياراً، يكمن الحديث حول نطوير نماذج جديدة باستخدام الوسائل التكنولوجية

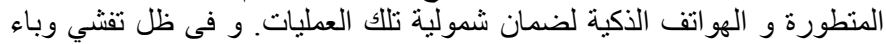

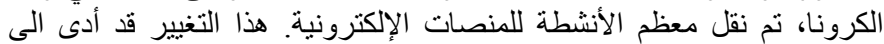

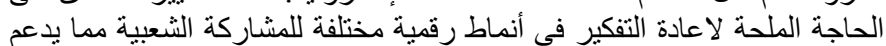

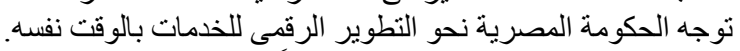

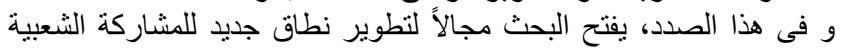

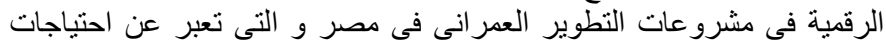

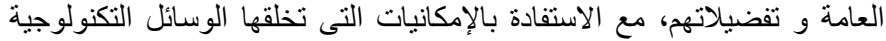

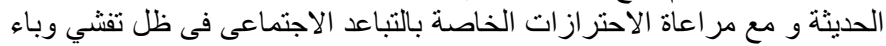

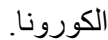

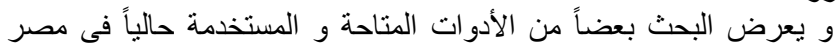

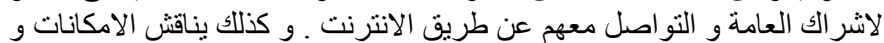

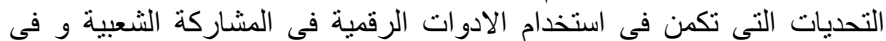

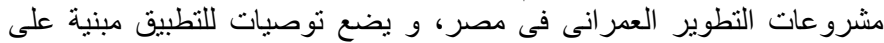

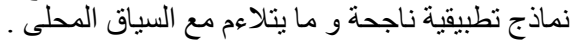

[30] "Government Complaints portal," 2021. https://www.shakwa.eg/GCP/Default.aspx (accessed Apr. 13, 2021).

[31] "Street Guards," 2021. http://www.streetguards.com/ (accessed Apr. 13, 2021).

[32] "Waste Collection App 'Dawar' Launches in Cairo | Egyptian Streets," Mar. 2021. https://egyptianstreets.com/2019/09/30/waste-collection-appdawar-launches-in-cairo-today/ (accessed Apr. 06, 2021).

[33] "IFES Election Guide Elections." https://www.electionguide.org/elections/?inst=\&cont=Egypt\&yr= (accessed Mar. 10, 2021).

[34] "| Human Development Reports." http://hdr.undp.org/en/countries/profiles/EGY (accessed Mar. 10, 2021).

Title in Arabic:

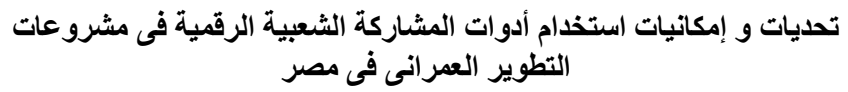

\section{Abstract in Arabic:}

على الرغم من التزايد العشو ائي المطرد و ما يتسبب فيه من مشكلات في إنى

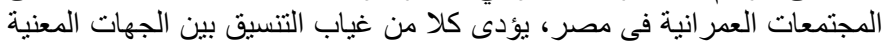

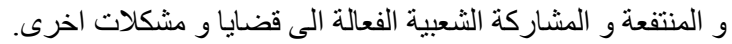

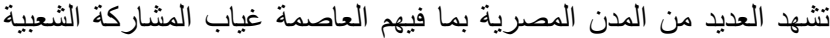

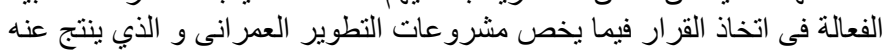

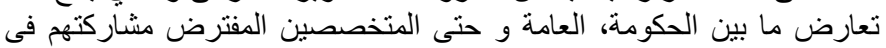
اتخاذ و تطبيق هذه القرارات. العديد من نماذج المشاركة المنارئ الشعبية يتم استخدامها

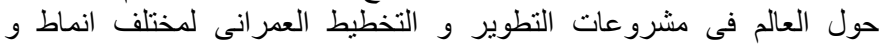
مستويات المشاركة الشعبية، و حيث انها اساسية فى كافة المشرو عات و لئر ليست 